\title{
On-line Global/WhO-European Regional Measles Nucleotide Surveillance
}

\author{
S Gnaneshan (saravanamuttu.gnaneshan@hpa.org.uk) ${ }^{1}, \mathrm{~K}$ E Brown ${ }^{1}$, J Green ${ }^{1}$, D W Brown \\ 1. Centre for Infections, Health Protection Agency London, United Kingdom
}

Measles virus causes an acute infection characterised by rash and fever. Measles infection is preventable by vaccination, but remains a significant cause of childhood mortality in the developing world with an estimated number of approximately 242,000 deaths by measles in 2006 [1].

The World Health Organization (WHO) is coordinating a global control programme for measles, and all WHO regions have identified targets for control or elimination of transmission of this disease. In the WHO European Region (WHO/Europe) the goal is to eliminate measles by 2010 [2]. Surveillance to document the elimination of transmission is in place, using case-based laboratory confirmation by detection of measles-specific IgM and by sequence characterisation of measles strains from outbreaks and chains of transmission. Measles virus is isolated and/or sequenced by the participating laboratories in the 'Global Measles and Rubella Laboratory Network' [3].

Following the success of HepSEQ [4], a public health database generated by the Centre for Infections of the United Kingdom Health Protection Agency, and a European Union-funded measles network called 'Enhanced Laboratory Surveillance of Measles' (ELSM) [5], we developed a web-based, quality-controlled database with epidemiological and nucleotide data for measles infection in the WHO/Europe region (MeaNS). The major objectives of the MeaNS initiative are to function as an epidemiological surveillance tool and to monitor progress of the measles control programme.

Sequence data from the 450 nucleotide region encoding the $\mathrm{C}$-terminal region of the measles virus nucleoprotein $(\mathrm{N})$ and, optionally, the complete nucleotide sequence of the haemagglutinin $(\mathrm{H})$ gene are deposited into MeaNS, together with epidemiological data. The data is quality checked and curated, first automatically by the database application and then manually by a curator. During the curation, specific identifiers called 'WHO names' [8] are created for each sample unless the names were provided by the depositors. In addition, the deposited sequences are assigned a genotype and a cluster identifying number by matching, respectively, against WHO reference sequences and the unique sequence clusters in the database.

Dynamic reports and graphical charts can be created on any userselected fields in the MeaNS database (eg: genotype or sequence variation in a geographical location or time period). Relevant data can be exchanged between MeaNS and either GenBank or the WHO database on Surveillance of measles and rubella $[6,7]$. Bioinformatics tools in MeaNS allow one to find identical or similar sequences, assign a genotype, display phylogenetic trees, and to temporally and spatially track measles transmission chains.

Regional laboratories from the European WHO Measles and Rubella Laboratory Network previewed the development of MeaNS, and the current release was well received. Further testing and development to enable uploading of sequence trace files and quality checking mechanisms are currently being undertaken, with an anticipated release for general use in mid-June 2008. The existing tools and the tools that are now being developed will be useful in the surveillance, sequence analysis, evolution, and genome annotation of measles.

Currently, MeaNS is the only known publicly available global database on measles nucleotide sequences. After registering the purpose of their interest, researchers can access MeaNS at www. hpa-bioinformatics.org.uk/Measles/Public/Web_Front/main.php.

\section{References}

1. Centers for Disease Control and Prevention. Progress in Global Measles Control and Mortality Reduction, 2000-2006. MMWR Morb Mortal Wkly Rep. 2007;56(47):1237-41.

2. World Health Organization Regional office for Europe. Strategic plan for measles and congenital rubella infection in the European Region of WHO. Copenhagen; 2003. Accessed 23 April 2008. Available from: http://www.euro. who.int/document/e81567.pdf

3. Featherstone D, Brown D, Sanders R. Development of the Global Measles Laboratory Network. J Infect Dis. 2003;187(Suppl 1):S264-9.

4. Gnaneshan S, Ijaz S, Moran J, Ramsay M, Green J. HepSEQ: International Public Health Repository for Hepatitis B. Nucleic Acids Res. 2007;35(DatabaseIssue):D367-70. Accessed 23 April 2008. Available from: http://www. hepseqresearch.org

5. Enhanced Laboratory Surveillance of Measles [homepage on the Internet]. London: Health Protection Agency. Accessed 23 April 2008. Available from: http:// www.elsm.net/elsm/Enhanced_Laboratory_Surveillance_of_Measles.htm

6. World Health Organization Regional office for Europe. Centralized information system for infectious diseases (CISID). Accessed 23 April 2008. Available from: http://data.euro.who.int/CISID/

7. World Health Organization Regional Office for Europe. Surveillance of measles and rubella. Accessed 23 April 2008. Available from: http://data.euro.who.int/ DownloadArea/VPI/MEA/E200605_MeaslesPage.pdf

8. Expanded Programme on Immunization (EPI). Standardization of the nomenclature for describing the genetic characteristics of wild-type measles virus. Wkly Epidemiol Rec. 1998;73(35):265-9.

This article was published on 8 May 2008.

Citation style for this article: Gnaneshan S, Brown KE, Green J, Brown DW. On-line Global/WHO-European Regional Measles Nucleotide Surveillance. Euro Surveill. 2008;13(19):pii=18861. Available online: http://www.eurosurveillance.org/ViewArticle. 2008;13(19):pii=18861. 